\title{
The anesthesia of trachea and bronchus surgery
}

\author{
Zehra Hatipoglu ${ }^{1}$, Mediha Turktan ${ }^{1}$, Alper Avci ${ }^{2}$ \\ ${ }^{1}$ Department of Anesthesiology and Reanimation, ${ }^{2}$ Department of Thoracic Surgery, Çukurova University Faculty of Medicine, Adana, Turkey \\ Contributions: (I) Conception and design: Z Hatipoglu; (II) Administrative support: Z Hatipoglu; (III) Provision of study materials or patients: All \\ authors; (IV) Collection and assembly of data: Z Hatipoğlu, M Türktan; (V) Data analysis and interpretation: Z Hatipoğlu, A Avci; (VI) Manuscript \\ writing: All authors; (VII) Final approval of manuscript: All authors. \\ Correspondence to: Zehra Hatipoglu, MD, Assist. Prof., Department of Anesthesiology and Reanimation, Çukurova University Faculty of Medicine, \\ Adana 01260, Turkey. Email: hatipogluzehra@gmail.com.
}

\begin{abstract}
The trachea and bronchus surgery is generally performed due to stenosis, traumatic injury, foreign body and tumors. Preoperative evaluation and anesthesia management are very important issues because of higher mortality and morbidity rates. Patients may be asymptomatic, but airway difficulties, hypoxia, stridor, cough, hemoptysis are common conditions in these patient population. The collaboration between the surgeon and the anesthesiologist is very substantial and necessary. Anesthetic techniques include various applications such as one lung ventilation, fiberoptic intubation, jet ventilation, and apneic oxygenation, general anesthesia with or without neuromuscular blockade. In this review, anesthesia management of the trachea and bronchus surgery is evaluated in the light of new knowledge.
\end{abstract}

Keywords: Anesthesia; trachea; bronchus; surgery

Submitted Sep 30, 2016. Accepted for publication Nov 03, 2016.

doi: $10.21037 /$ jtd.2016.11.35

View this article at: http://dx.doi.org/10.21037/jtd.2016.11.35

\section{Introduction}

The trachea, main stem bronchi, bronchus intermedius and lobar bronchus make up the central airway. Disorders of central airway lead to disturbing symptoms such as cough, dyspnea, stridor, tachypnea, and hemoptysis (1-3). The trachea and bronchus surgery are mainly applied to stenosis, traumatic injury and tumors (4). Surgical approaches are one treatment option for central airway obstruction and other disorders. These approaches include complex interventions requiring one lung ventilation or cardiopulmonary bypass $(\mathrm{CPB})$ as well as non-complex interventions such as dilatation (5). Anesthesia management for patients undergoing trachea and bronchus surgery is important in terms of protection of airway integrity and anesthesia maintenance. Therefore, the aim of this review is to share recent developments regarding anesthesia for tracheal and bronchus surgeries.

\section{Anatomy of the trachea and bronchus}

The trachea is a semiflexible tube extending from the sixth through the seventh cervical vertebrae to the fourth through fifth thoracic vertebrae. It is 10 to $14 \mathrm{~cm}$ in length with diameter of 1 to $2.7 \mathrm{~cm}$. The trachea consists of two portions: the extrathoracic trachea is above the suprasternal notch, and it is 4 to $5 \mathrm{~cm}$ in length. The intrathoracic trachea is below the suprasternal notch, and it is $6-9 \mathrm{~cm}$ in length.

The trachea divides into two parts at the level of the fifth through sixth thoracic vertebrae, right and left main stem bronchus. The right main stem bronchus is wider and shorter than the left main stem bronchus. It is also separated from the trachea by steeper angle (6-9).

\section{Tracheal stenosis}

The etiology of tracheal stenosis involves many factors. Tracheal stenosis most commonly occurs post-intubation and post-tracheostomy, and incidence ranges from $10 \%$ to $22 \%$ (7). Congenital diseases (tracheomalacia, webs, vascular rings), chronic inflammatory diseases (sarcoidosis, amyloidosis), infectious diseases (tuberculosis, 
rhinoscleroma, papillomas), collagen vascular diseases (Wegener's granulomatosis, lupus), malign tumors, and foreign body aspiration are other causes $(7,8)$. Malign tumors include primary tracheal tumor (squamous cell carcinoma, adenoid cystic carcinoma, and mucoepidermoid carcinoma), metastatic tumor and masses of adjacent organs (thyroid, larynx, lung, esophagus and mediastinal masses) (8). Most of these reasons lead to intraluminal obstruction. The tracheal mucosa has been infiltrated by benign or malign tissues. These formations within the lumen will cause a blockage later. However, extraluminal obstruction of the trachea occurs as a result of extrinsic compression or submucosal infiltration of the mass. Unlike intraluminal obstruction, the mucosa is intact. Distinct from these obstructions is dynamic airway collapse that occurs because of weakness of the posterior tracheal membrane. The place of obstruction is important in terms of the surgical approach and anesthetic management. Endoscopic interventions, such as mechanical debulking, microdebrider, cryocanalization, electrocautery, and tracheal resection are surgical methods applied to the intraluminal obstruction. The endoscopic procedures are applied in conjunction with rigid bronchoscopy. Surgical approaches for extraluminal obstruction include the excision of the mass, causing compression and endoscopic interventions (e.g., stent placement). Similarly, it may also apply endoscopic intervention for dynamic airway collapse (9).

\section{Preoperative assessment}

Primarily, patients with tracheal stenosis are evaluated with regard to medical history and general physical examination. The airway and pulmonary systems, in particular, should be assessed in detail, because they usually reveal nonspecific respiratory symptoms that include stridor, hoarseness, wheezing, progressive dyspnea, and reduced exercise tolerance $(10,11)$. These symptoms occur $8 \mathrm{~mm}$ below or at a $50 \%$ reduction in the internal diameter of the trachea. Furthermore, if the internal diameter is $5-6 \mathrm{~mm}$, inspiratory stridor is seen at rest. It is also important to evaluate the patient's respiratory function in the supine position. If the patient's breathing pattern is disrupted in the supine position, the anesthesia should be initiated in the appropriate position for the patient (8). Additionally, the patient should be questioned regarding the use of steroid and previous radiation therapy. Steroids may be associated with airway anastomotic dehiscence and delay in wound healing. Radiotherapy to the neck region can cause restricted neck movement (10).

Other investigated parameters are pulmonary function tests, arterial blood gas analysis, posteroanterior and lateral chest radiography, computerized tomography (CT), magnetic resonance imaging, and flexible bronchoscopy $(12,13)$. Pulmonary function tests, particularly flow-volume loops, may provide information about the degree of the tracheal stenosis, but it is not specific and sensitive for diagnosis for diagnosis. Furthermore, airway crisis may be triggered during these tests. Reduced forced expiratory volume in one second (FEV1) can be interpreted in favor of obstruction $(13,14)$. Variable intrathoracic obstructions indicate flattening in the expiratory limb of the flow-volume loop. Extrathoracic obstructions indicate flattening in the inspiratory limb of the flow-volume loop. However, fixed intra- and extrathoracic obstructions show flattening in the inspiratory and expiratory limbs $(2,7)$. A baseline value of arterial blood gas analysis may be a guide for postoperative management.

\section{Monitoring}

Standard monitoring includes electrocardiography (ECG), non-invasive blood pressure, pulse oximetry, and end-tidal carbon dioxide $\left(\mathrm{ETCO}_{2}\right)$ measurement (11). However, invasive monitoring may be required for patients undergoing tracheal resection. Arterial catheterization is used to evaluate hemodynamic and arterial blood gas changes, and the left radial artery is frequently preferred for catheterization (8). For vascular access, a peripheral intravenous (IV) (18-20 gauge) or central venous catheter may be used. Peripheral access will be sufficient for fluid management. However, the use of a central venous catheter may be necessary with inotropic drugs and in patients with cardiac problems. In such a case, the femoral or subclavian vein is most often used for catheterization $(8,14)$.

\section{Anesthesia management in rigid bronchoscopy}

Rigid bronchoscopy is the initial phase of surgical approaches for tracheal lesions, and it is difficult to tolerate by an awake patient. Therefore, for these patients, general anesthesia is recommended in the operating room. Premedication should be avoided in patients with severe stenosis. The use of antisialogogues is not routine to reduce secretions. Furthermore, these drugs can increase the degree of stenosis by creating a mucous plug $(11,12)$. 
The surgeon should be available when induction begins, and pediatric- and adult-sized rigid bronchoscopes must be present in the operating room. The patient is placed on the operating table in the supine position. The roll is placed below the shoulder, and the neck should be hyperextended (15). After preoxygenation, IV (e.g., propofol, thiopental) and inhalation agents are used for anesthesia induction. In this instance, anesthetic agents are administered by titration, and after adequate anesthesia depth is achieved, local anesthetics such as lidocaine, may be administered into the pharynx and trachea to decrease the airway's response to instrumentation during rigid bronchoscopy (12). There are two important issues regarding ventilation: spontaneous ventilation during induction generates negative inspiratory intratracheal pressure, and it increases stenosis. Positive pressure ventilation creates positive intratracheal pressure. Therefore, positive pressure ventilation is preferable in patients with extrathoracic stenosis (e.g., tracheomalacia), whereas spontaneous ventilation may be applied in intrathoracic stenosis $(14,16)$. After providing airway security, a dose-dependent, fast-acting nondepolarizing, or depolarizing muscle relaxant may be used as a neuromuscular blocking agent. Recent reviews reported that, despite the side effects of succinylcholine, it is superior to rocuronium in terms of intubation $(17,18)$.

Total intravenous anesthesia (TIVA) or volatile agents can be used for anesthesia maintenance. Options for TIVA are propofol, remifentanil, ketamine, and dexmedetomidine. These drugs are implemented through target controlled infusion systems. TIVA is different from volatile agents used during ventilation. In the endoscopic interventions, several ventilation techniques are needed, and apneic periods or air leaks from the bronchoscope may occur during the procedures (19). At this stage, volatile anesthetics constitute a problem because of distribution, and maintenance of anesthesia is interrupted. However, TIVA does not cause such a problem because of continuing anesthesia (20). If volatile anesthetics are preferred, additional IV anesthetics should be applied during the apneic periods (11). Sevoflurane can be selected as volatile anesthetic because its effects are less irritating than those of other volatile anesthetics (21). During ventilation, a mixture of nitrous oxide $\left(\mathrm{N}_{2} \mathrm{O}\right)$-oxygen $\left(\mathrm{O}_{2}\right)$ or oxygen-air can be used. Further, a bispectral index (BIS) may be employed to assess the depth of anesthesia in patients receiving TIVA (20).

It should be noted that tracheobronchial surgery requires collaboration between the surgeon and the anesthesiologist. Such cooperation is especially important at the ventilation stage. Several ventilation techniques can be applied during rigid bronchoscopy. These include apneic oxygenation, spontaneous ventilation, controlled ventilation, manual jet ventilation (low-frequency jet ventilation), and highfrequency jet ventilation (HFJV). Manual jet ventilation is the most commonly used ventilation technique during rigid bronchoscopy (19). HFJV (60-600 cycles/min) is provided by ventilators, and it diminishes airway pressures and the risk of barotrauma $(14,22)$. Ventilation is performed with connection placed onto the bronchoscope.

If tracheal resection is planned after rigid bronchoscopy, the patients are intubated. If there is stenosis in the upper trachea, an appropriate-sized endotracheal tube (ETT) may remain at the level of the vocal cord, which results in an air leak. Therefore, a small ETT can be used, but it may hypercapnia. If there is stenosis in the mid-trachea, an ETT is advanced above the stenosis. Tracheostomy may, rarely, be necessary for a patent airway $(11,23)$. However, upper tracheal resection may be also performed through laryngeal mask airway (LMA). But it has some disadvantages: the patients who critical airway stenosis may be inadequate ventilation $(10,24)$.

\section{Anesthesia management in the tracheal and carinal resection}

Premedication, drugs used in anesthesia management and position are similar with rigid bronchoscopy. For upper tracheal lesions, the trachea is explored through cervical incision (color incision, U-shaped) (23). The location of the incision is between the lower part of the cricoid cartilage and the sternal notch. Cervico-mediastinal incision is applied for middle tracheal lesions. For lower tracheal lesions, the surgical approach is median sternotomy or right thoracotomy $(4,25)$.

During anesthesia induction, the ETTs must be prepared for intubation (11). For the correct placement of the ETT, fiberoptic bronchoscope (FOB) can be used (12). In the presence of upper tracheal lesion, ETT is placed in the trachea above the lesion. Surgical processing is initiated after sterilization of the surgical site following intubation. The trachea is exposed, and the first incision is applied at the distal end of the obstruction (26) (Figure 1). After confirming the ETT, it is withdrawn into the proximal trachea. Simultaneously, a sterile ETT is placed into the distal trachea by the surgeon (4) (Figure 2). This tube is connected to a sterile anesthetic circuit, across the surgical field. Ventilation is maintained by the anesthesiologist and 


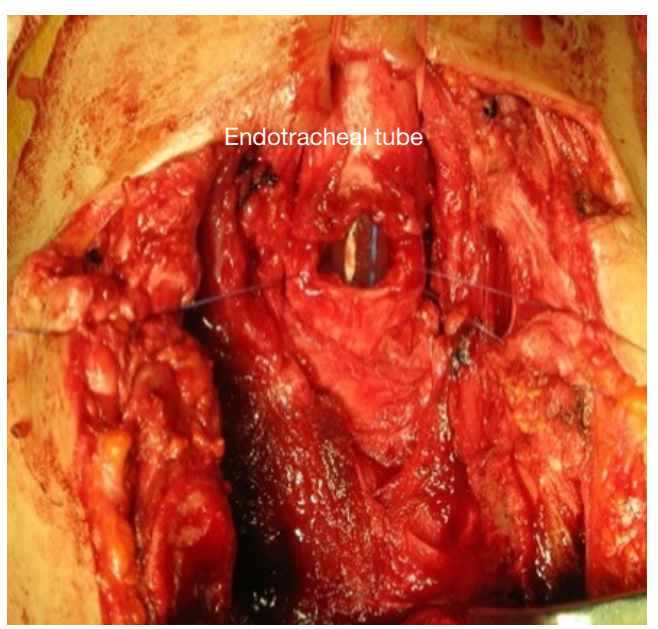

Figure 1 Endotracheal tube during tracheal incision.

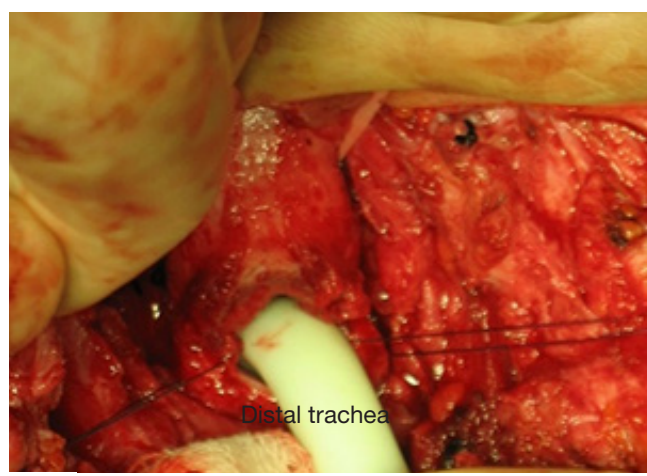

Figure 2 Distal endotracheal tube.

confirmed by evaluating chest inflation, peripheral oxygen saturation, $\mathrm{ETCO}_{2}$, and blood gas analysis $(8,11)$. Resection of the tracheal lesion is completed with circumferential dissection, and anastomosis is then started. After surgery, patients are reintubated and ETT is removed from the distal trachea. The intubation tube is advanced to the bottom of the anastomosis $(4,26)$ (Figure 3). Furthermore, retrograde intubation may be performed via the flexible catheter; therefore, contamination of the surgical field may be prevented $(4,8)$. The anastomosis is tested in terms of air leak. Therefore, the patients should be ventilated with $20-30 \mathrm{cmH}_{2} \mathrm{O}$ pressure $(11,15)$.

Ventilation may be provided through the ETT, jet ventilation catheter, tracheostomy cannula, LMA, and different ventilation strategies can be performed during tracheal resection (12). These strategies include manual jet ventilation and high-frequency ventilation $(5,27)$. Manual

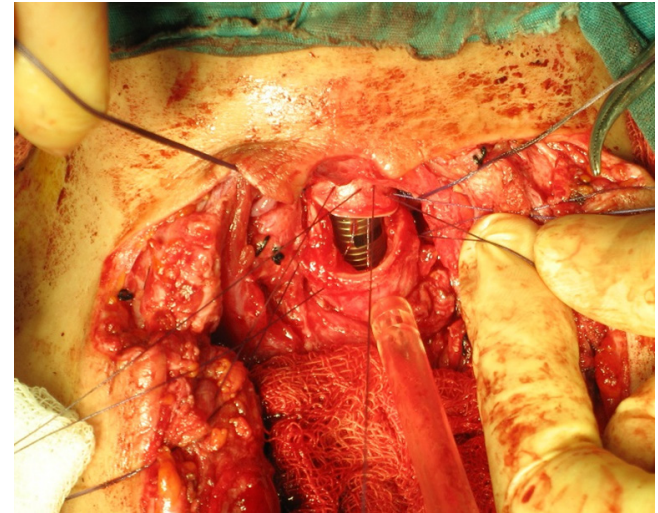

Figure 3 Endotracheal tube during anastomosis.

jet ventilation applies in various ways, such as ETT and catheter. This ventilation provides high tidal volume but, it carries the risk of hypercapnia (5). Small-bore ETT and catheter are used for high-frequency, and it can be used in three different modes: high-frequency positive pressure ventilation (HFPPV), high-frequency jet ventilation (HFJV), and high-frequency oscillation ventilation (HFOV). If diameter of the distal trachea is narrow and there is difficulty during the surgical procedure, HFPPV can be performed in these patients (27). HFOV is implemented most often for lung surgery, such as lobectomy and pneumonectomy. Advantages of high-frequency ventilation are as follows: good gas exchange, reduced ventilation/perfusion mismatch and atelectasis due to auto positive end-expiratory pressure, and minimal hemodynamic changes (5). LMA can be used in airway management of tracheal resection. Biro et al. reported that LMA is a safe approach for ventilation and surgical exposure in serious upper-tracheal stenosis (28).

Anesthesia management for distal trachea and carina obstructions is slightly different than that for upper tracheal lesions. The surgery approach for these obstructions is right posterolateral thoracotomy. Ventilation strategies during surgery involve one-lung ventilation (OLV), extracorporeal membrane oxygenation (ECMO), or CPB $(5,29)$. Different approaches are used for OLV. After the ETT is pulled above the lesion during surgery procedure, the endobronchial blocker, ETT or single lumen endobronchial tube may be preferred for placement into the left mainstem bronchus $(5,12,21)$. According to the airway devices used, low-frequency jet ventilation or low tidal volume ventilation are applied during resection $(12,30)$. ECMO is another alternative strategy for gas exchange. It can be performed veno-venously or veno-arterially (29). 
At the end of resection and reconstruction, ETT is placed above the anastomosis line, and ventilation is conventionally maintained (11).

If the patient's respiratory effort is adequate, extubation should be planned in the operating room. Prolonged intubation can disrupt the anastomosis line because of positive pressure ventilation and tracheal irritation (25). However, in the patients who underwent carinal resection and prolonged operation, postoperative mechanical ventilation may be required for respiratory support (8). Before extubation, neck flexion is supported with a suture between the chin and the manubrium sterni. The aim is to decrease anastomotic tension (15). In the extubation period, anesthesia preparations should be made for possible airway problems. Because emergent intubation and reintubation may be needed, intubation should be made through $\mathrm{FOB}(5,8)$.

\section{Pain management}

In patients with cervical incision, postoperative analgesia options may include systemic opioids and nonsteroidal anti-inflammatory drugs (NSAIDs). Epidural analgesia, paravertebral and intercostal blocks, and systemic analgesia, such as opioids and NSAIDs, may be preferred for patients with thoracotomy $(12,25,31,32)$.

\section{Postoperative care}

During the postoperative period, the patient's head should be kept elevated in a supine position to reduce swelling (5). Postoperative pulmonary care is important for these patients. Possible lung pathologies, such as pneumothorax and atelectasis, are evaluated by a posteroanterior chest radiograph. Also important is removal of tracheal secretions. For this reason, chest physiotherapy may be recommended (15). On the fifth through seventh postoperative days, anastomosis healing is assessed by FOB. After suture which used for neck flexion is cut, the patient's discharge from hospital is planned (25).

\section{Complications}

The literature reports average mortality rates of $3 \%$ and $2-20 \%$, respectively, in tracheal and carinal resection $(8,30)$. Postoperative complications can be seen in the early late period. Early complications involve respiratory distress and vocal cord paralysis. During surgery, the recurrent laryngeal nerve may be damaged. This situation may result in vocal cord paralysis after surgery, and may lead to hoarseness and dyspnea (8). Later complications can be anastomotic, such as granulation tissue, necrosis, and dehiscence as well as hemoptysis $(8,30)$.

\section{Tracheobronchial injuries (TBIs)}

TBIs are rare, but may be fatal. Penetrating or blunt trauma to the chest or neck lead to TBIs. The reported incidence of TBIs is $0.5 \%$ to $2 \%$. Injuries caused by blunt trauma are seen in the intrathoracic trachea and mainstem bronchus, whereas penetrating trauma affects the extrathoracic trachea. Symptoms occurring in airway injuries involve dyspnea, respiratory failure, hoarseness, and dysphonia. Subcutaneous emphysema, pneumothorax, and hemoptysis can be seen in patients with trauma. Chest radiography, neck and chest CT are required for diagnosis. FOB is the best method to assess the size and location of injury.

TBIs usually require multidisciplinary approach due to possible injuries to multiple organs. Airway management is extremely important in patients with TBIs. These patients may require immediate intubation because of respiratory failure and hemodynamic instability. At this stage, FOB guided endotracheal intubation would be a rational approach. In some cases, ventilation is accomplished through tracheostomy, and intubation is accomplished through an open neck wound and nasotracheal intubation (33).

Anesthesia management of these patients should be done in collaboration with the surgeon and the anesthesiologist. Airway management has been mentioned above. In addition, tube selection is an important detail. Double-lumen tube is not recommended for intubation. Long ETTs, singlelumen tubes, endobronchial blockers are options used for successful ventilation (33). Anesthesia maintenance and ventilation strategies are similar with tracheal stenosis (see trachea stenosis). Manual jet ventilation, HFJV, one lung ventilation and $\mathrm{CPB}$ can be performed according to the localization and size of tracheal injury $(34,35)$.

Postoperative care involves closely respiratory and hemodynamic monitoring of patients (34).

\section{Bronchus surgery}

Bronchial surgery is one of the most commonly used procedures in thoracic surgery and is generally applied in instances of tumors, foreign bodies, and trauma. Endobronchial tumors and foreign bodies may lead to bronchial obstruction, severe dyspnea, and finally, collapse 
of the affected lung. Preoperative evaluation of the patients is very important for bronchus surgery and is similar to tracheal surgery. Bronchoscopic techniques, including rigid bronchoscopy or flexible fiberoptic bronchoscopy, are used for laser therapy, foreign-body removal, and the placement or control of the lung isolation device.

\section{Bronchus tumors}

Bronchus tumors are generally seen in two forms: primer or recurrent lung cancer and metastases from other organ tumors (36). The most common symptoms are dyspnea, cough, and hemoptysis. Pneumonia, abscess, and recurrent infections can be observed and life-threatening stridor may occur in obstruction of the main bronchus. Distal tumors are often asymptomatic, and a diagnosis is usually established through routine radiological examination. The treatments include laser therapy, bronchial stent placement, photodynamic therapy, argon beam coagulation, radiotherapy, and surgical excision with or without bronchoscopy, and a combination of these techniques (36-38).

Laser therapy is one of the most commonly used treatments for bronchial tumors. However, if sufficient measures are not taken, serious risks may occur, such as corneal and retinal damage, airway fire, gas embolism, perforation of an organ or vessel, airway hemorrhage, pneumothorax, and tracheoesophageal fistula (39). During laser therapy, it is recommended that all operating room personnel (doctor, nurse, technicians, etc.) use special eyeglasses. The patient's eyes must be protected by closing the eyelids with tape and saline-soaked pads. Windows should be covered and warning signs should be placed outside the door.

Airway fire is rare but most feared complication associated with laser application. The use of special laserresistant tracheal tubes and inflation of the ETT cuff with saline and a colored indicator are suggested for the prevention of the fire. The use of oil-base balm to increase the lubricity of the ETTs is dangerous because of the combustible nature of these substances. Minimal oxygen concentration (inspired oxygen concentration $<40 \%$ ) allows for sufficient oxygenation of the patients to be used to avoid potential airway damage (40-42). A mixture of oxygen-air is more suitable than an oxygen-nitrogen mixture, which is highly combustible (43). In the event of an airway fire, laser therapy and ventilation are terminated, the oxygen source is removed, and the patient is extubated. The patient is then ventilated with a face mask, and airway is evaluated for possible damage with rigid or flexible bronchoscopy. If damage is suspected, the patients are reintubated, tracheotomy may be required, and steroids may be used to decrease mucosal edema. In addition, inhale bronchodilators may help to reduce possible bronchospasm.

Laser therapy is performed with fiberoptic or rigid bronchoscopy. Several anesthetic approaches-awake or general anesthesia and nasal or oral intubation-are applied for flexible bronchoscopic intervention. In the presence central airway obstruction, the first choice may be fiberoptic bronchoscopy awake or step-by-step general anesthesia protecting spontaneous ventilation (44). Premedication with sedative drugs is not recommended in patients with airway obstruction but antisialagogues and anticholinergic drugs may be used. Awake technique can be performed with topical anesthesia via nebulizer, aerosol, or local anesthetics-soaked pads, local anesthesia via laryngeal or glossopharyngeal nerve blocks or direct application of local anesthetic as spray via bronchoscope (45). The use of an ETT with a large internal diameter facilitates the fiberoptic placement and adequate ventilation of the patient. LMA can be used for the fiberoptic technique, especially in patients with difficult airways, and LMA also leads to lower airway resistance during bronchoscopy $(46,47)$. IV or inhalation agents are preferred for anesthesia induction and maintaince. Propofol helps to suppress the laryngeal reflex and provides better clinical conditions than the other IV agents $(48,49)$. If paralysis is required, shortacting neuromuscular blocking agents should be preferred because partial airway obstruction may convert to complete obstruction $(16,50)$. These interventions have minimal postoperative pain and only short-acting opioids are recommended.

Rigid bronchoscopy, the other alternative technique for laser therapy, provides better visibility and airway control because of ventilating instrumentation and a minimal fire hazard (50). In addition, general anesthesia with neuromuscular blockade, spontaneous ventilation with topical anesthesia or nerve blocks, apneic oxygenation, and jet ventilation are applicable techniques for rigid bronchoscopy $(51,52)$. Any movement of the patient during bronchoscopy may result in serious injury, but the use of a neuromuscular blocker may be dangerous in patients with partial airway obstruction. Succinylcholine is a suitable neuromuscular blocker agent because of its short-acting properties. Nondepolarizing agents may be preferred for prolong interventions. During rigid bronchoscopy, the bronchoscopist is exposed to the anesthetic gases, and 
higher $\mathrm{PaCO}_{2}$ values may be observed with positive pressure ventilation due to interruption of the ventilation (50). TIVA allows for the provision of adequate anesthesia without interruption, and this anesthetic regimen also prevents the contamination of the operating room with anesthetic gases. Several other complications of rigid bronchoscopy include soft-tissue injury (mouth, lips, tongue etc.), tooth damage, sore throat, airway perforation, hemorrhage, airway edema, and laryngospasm.

The most common monitorization method for bronchoscopy (flexible or rigid) is pulse oxymetry because desaturation is a common and important condition in this intervention. End-tidal $\mathrm{CO}_{2}$ values are not reliable because the patient's airway is open to the atmosphere. In the prolong process, arterial blood gas analysis may be beneficial. At the end of the bronchoscopy, the patients may be extubated and ventilated via a face mask. However, the patients with respiratory failure are again intubated after the procedure, and corticosteroids (methylprednisolone or dexamethasone) and inhaled epinephrine may be used in edematous airway situations. When respiratory function improves, the patients are extubated.

Bronchial stents are often used in bronchial obstruction due to bronchial tumors and stricture. Deep IV anesthesia with flexible bronchoscopy or general anesthesia with neuromuscular blockage can be preferred to placement of stents. This procedure is performed for both extrinsic compression and intraluminal stenosis in adult and pediatric patients without pain $(53,54)$.

Photodynamic therapy can be performed under general anesthesia or topical anesthesia plus IV anesthesia. There is no risk of airway fire, and the patients may be ventilated with $100 \%$ oxygen if required.

Massive hemoptysis or bleeding due to bronchial tumors is a feared clinical condition. The main goal of anesthesia includes volume resuscitation, the separation of bleeding lungs, the protection of normal lungs, and providing sufficient oxygenation. In addition to standard monitoring (heart rate, non-invasive blood, and pulse oxymetry), invasive arterial catheterization and central venous catheterization are recommended. Large diameter IV catheters provide rapid fluid administration. Before anesthesia induction and intubation, the patient should be bleeding lung in a dependent position. This position prevents contamination of the healthy lung. Rapid and safe airway management must be provided in these patients. Fiberoptic awake intubation may be used, although visualization is difficult because of bleeding. Single-lumen endotracheal intubation followed by endobronchial blocker, main bronchial intubation of unaffected lung with fiberoptic bronchoscopy, or doublelumen intubation may be used to separate of the lungs.

\section{Bronchus foreign bodies}

Bronchial foreign body aspiration is less common in adults than in children. It is generally seen in elderly male patients with Alzheimer's disease, psychiatric illness, or head trauma $(55,56)$. The clinical symptoms include cough, dyspnea, wheezing, shock, hemoptysis, cardiorespiratory arrest, but the majority of patients may be asymptomatic. Early identification and intervention are crucial because it may cause life-threating complete or incomplete airway obstruction (56). Finally, respiratory distress, pneumothorax, asphyxia, lung abscess, pneumonia, asthma, bronchiectasis, and atelectasis may occur as complications (57). Bronchopleural and bronchopleural cutaneous fistulas and subcutaneous emphysema are possible rare complications because of foreign body aspiration $(58,59)$. The definitive diagnosis includes chest X-ray imaging and CT (60). In chronic aspiration history, granulation tissue may occur around the foreign body. Rigid or flexible bronchoscopy plays a role both diagnosis and removal of the foreign body. Emergency tracheostomy may be required in the case of complete bilateral occlusion (61). If bronchoscopy fails, open thoracotomy may be used for successful removal. The patients are at risk in emergency cases for full stomach, and a large-bore gastric tube must be inserted before tracheostomy, but if the patient has respiratory and hemodynamic stability, the intervention may be delayed (62). An inhalation agent is generally used for anesthesia induction, but another option is controlled IV induction. Anesthesia maintenance is performed with IV or inhalation agents; neuromuscular blocking drugs may be used if necessary (48-50). During the removal of foreign body, falling back to tracheobronchial area is a life-threating condition (62). Therefore, adequate depth of anesthesia must be provided before removal of the body. If oxygenation and ventilation are impossible, ECMO may be a life-saving method (63).

\section{Bronchopleural fistula}

Bronchopleural fistula is rare but life-threating complication of thoracic surgery (especially pneumonectomy and lobectomy) and is associated with a higher risk of mortality and morbidity. The most common causes are rupture of 
pulmonary structure into the pleural space (lung abscess, bronchus, cyst, parenchymal tissue, bulla), bronchial destruction (carcinoma, inflammation), stump dehiscence after pulmonary resection, and erosion of the pulmonary artery or vascular suture line (64). Incorrect placement of the enteral feeding tube and esophageal stent migration are the other uncommon causes $(65,66)$. Clinical observation is very important factor for diagnosis. After thoracic surgery, dyspnea, emphysema, purulent drainage, permanent air leak, and tracheal deviation should be suspected of bronchopleural fistula. Fewer and purulent sputum may be first symptoms after removal of the chest tube. A decrease of the fluid level and new air-fluid level are seen in the X-ray imaging. The diagnosis is confirmed with bronchoscopy, methylene blue injection, inhalation of xenon, scintigraphy with Tc-99m DTPA, and inhalation of $\mathrm{O}_{2}-\mathrm{N}_{2} \mathrm{O}$ mixture $(67,68)$. In early postpneumonectomy patients, resuturation may be possible, but in delayed cases, open drainage or muscular flap may be necessary. If non-pneumonectomy bronchopleural fistula, treatment includes chest tube or surgical resection.

Anesthesia management may be complicated in these cases. The primary aims are the protection of healthy lung and providing oxygenation. Lung isolation devices (doublelumen ETTs or bronchial blockers) must be used for lung protection, especially with a larger fistula. Excessive higher pressure should be avoided because positive pressure ventilation may lead to tension pneumothorax. A chest tube should be placed before the induction of anesthesia as a measure for tension pneumothorax. Inadequate ventilation may occur because an air leak. Awake fiberoptic intubation with double-lumen or single-lumen ETTs, spontaneous ventilation until lung isolation, thoracic epidural anesthesia with IV sedation and HFJV may be used in patients with bronchopleural fistula (69).

\section{Acknowledgements}

None.

\section{Footnote}

Conflicts of Interest: The authors have no conflicts of interest to declare.

\section{References}

1. Beamis JF Jr. Interventional pulmonology techniques for treating malignant large airway obstruction: an update. Curr Opin Pulm Med 2005;11;292-5.

2. Williamson JP, Phillips MJ, Hillman DR, et al. Managing obstruction of the central airways. Intern Med J 2010;40:399-410.

3. Theodore PR. Emergent management of malignancyrelated acute airway obstruction. Emerg Med Clin North Am 2009;27:231-41.

4. Maniwa Y. Surgical treatment of air way disease. J Thorac Dis 2016;8:E78-82.

5. Pinsonneault C, Fortier J, Donati F. Tracheal resection and reconstruction. Can J Anaesth 1999:46;439-55.

6. Brand-Saberi BE, Schäfer T. Trachea: anatomy and physiology. Thorac Surg Clin 2014;24:1-5.

7. Barros Casas D, Fernández-Bussy S, Folch E, et al. Nonmalignant central airway obstruction. Arch Bronconeumol (English Edition) 2014;50:345-54.

8. Hobai IA, Chhangani SV, Alfille PH. Anesthesia for tracheal resection and reconstruction. Anesthesiol Clin 2012;30:709-30.

9. Gorden JA, Ernst A. Endoscopic management of central airway obstruction. Semin Thorac Cardiovasc Surg 2009;21:263-73.

10. Sandberg W. Anesthesia and airway management for tracheal resection and reconstruction. Int Anesthesiol Clin 2000;38:55-75.

11. Young-Beyer P, Wilson RS. Anesthetic management for tracheal resection and reconstruction. J Cardiothorac Anesth 1988;2:821-35.

12. Mentzelopoulos SD, Tzoufi MJ. Anesthesia for tracheal and endobronchial interventions. Curr Opin Anaesthesiol 2002;15:85-94.

13. Wood DE. Management of malignant tracheobronchial obstruction. Surg Clin N Am 2002;82:621-42.

14. Wiedemann K, Männle C. Anesthesia and gas exchange in tracheal surgery. Thorac Surg Clin 2014;24:13-25.

15. D'Cunha, J, Maddaus MA. Surgical treatment of tracheal and carinal tumors. Chest Surg Clin N Am 2003:13;95-110.

16. Nouraei SAR, Giussani DA, Howard DJ, et al. Physiological comparison of spontaneous and positivepressure ventilation in laryngotracheal stenosis. $\mathrm{Br} \mathrm{J}$ Anaesth 2008;101:419-23.

17. Ghezel-Ahmadi V, Ghezel-Ahmadi D, Mangen J, et al. Comparing Patient Satisfaction and Intubating Conditions Using Succinylcholine or Low-Dose Rocuronium for Rigid Bronchoscopy: A Randomized Study. Thorac Cardiovasc Surg 2015;63:526-32. 
18. Perry JJ, Lee JS, Sillberg VA, et al. Rocuronium versus succinylcholine for rapid sequence induction intubation. Cochrane Database Syst Rev 2008;16:CD002788.

19. Pathak V, Welsby I, Mahmood K, et al. Ventilation and anesthetic approaches for rigid bronchoscopy. Ann Am Thorac Soc 2014;11:628-34.

20. Purugganan RV. Intravenous anesthesia for thoracic procedures. Curr Opin Anaesthesiol 2008;21:1-7.

21. Slinger PD, Campos JH. Anesthesia for Thoracic Surgery. In: Miller RD. editor. Miller's Anesthesia, 7th Edition. Philadelphia: Churchill Livingstone, 2009:1864.

22. Pawlowski J. Anesthetic considerations for interventional pulmonary procedures. Curr Opin Anaesthesiol 2013;26:6-12.

23. Gómez-Caro A, Morcillo A, Wins R, et al. Surgical management of benign tracheal stenosis. Multimedia Man Cardiothorac Surg 2011;2011:mmcts-2010.004945.

24. Adelsmayr E, Keller C, Erd G, et al. The laryngeal mask and high-frequency jet ventilation for resection of high tracheal stenosis. Anesth Analg 1998;86:907-8.

25. Blasberg JD, Wright CD. Surgical considerations in tracheal and carinal resection. Semin Cardiothorac Vasc Anesth 2012;16:190-5.

26. Geffin B, Bland J, Grillo HC. Anesthetic management of tracheal resection and reconstruction. Anesth Analg 1969;48;884-90.

27. Daumerie G, Su S, Ochroch EA. Anesthesia for the patient with tracheal stenosis. Anesthesiol Clin 2010;28:157-74.

28. Biro P, Hegi TR, Weder W, et al. Laryngeal mask airway and high-frequency jet ventilation for the resection of a high-grade upper tracheal stenosis. J Clin Anesth 2001;13:141-3.

29. Smith IJ, Sidebotham DA, McGeorge AD, et al. Use of extracorporeal membrane oxygenation during resection of tracheal papillomatosis. Anesthesiology 2009;110:427-9.

30. Gonfiotti A, Jaus MO, Barale D, et al. Carinal resection. Thorac Surg Clin 2014;24:477-84.

31. Yeung JH, Gates S, Naidu BV, et al. Paravertebral block versus thoracic epidural for patients undergoing thoracotomy. Cochrane Database Syst Rev 2016;2:CD009121.

32. Khalil KG, Boutrous ML, Irani AD, et al. Operative Intercostal Nerve Blocks With Long-Acting Bupivacaine Liposome for Pain Control After Thoracotomy. Ann Thorac Surg 2015;100:2013-18.

33. Karmy-Jones R, Wood DE. Traumatic injury to the trachea and bronchus. Thorac Surg Clin 2007;17:35-46.

34. Sengupta S, Saikia A, Ramasubban S, et al. Anaesthetic management of a patient with complete tracheal rupture following blunt chest trauma. Ann Card Anaesth 2008;11:123.

35. Kawaguchi T, Kushibe K, Takahama M, et al. Bluntly traumatic tracheal transection: usefulness of percutaneous cardiopulmonary support for maintenance of gas exchange. Eur J Cardiothorac Surg 2005;27:523-5.

36. Hosni A, Bezjak A, Rink A, et al. High Dose Rate Brachytherapy as a Treatment Option in Endobronchial Tumors. Lung Cancer Int 2016;2016:3086148.

37. Rizzardi G, Marulli G, Bortolotti L, et al. Sleeve resections and bronchoplastic procedures in typical central carcinoid tumours. Thorac Cardiovasc Surg 2008;56:42-5.

38. Venuta F, Rendina EA, Giacomo TD, et al. Nd:YAG laser resection of lung cancer invading the airway as a bridge to surgery and palliative treatment. Ann Thorac Surg 2002;74:995-8.

39. Smith LP, Roy S. Operating room fires in otolaryngology: risk factors and prevention. Am J Otolaryngol 2011;32:109-14.

40. Roy S, Smith LP. Surgical fires in laser laryngeal surgery: are we safe enough? Otolaryngol Head Neck Surg 2015;152:67-72.

41. Eichhorn JH, Eisenkraft JB. Expired oxygen as the unappreciated issue in preventing airway fires: getting to "never". Anesth Analg 2013;117:1042-4.

42. Remz M, Luria I, Gravenstein M, et al. Prevention of airway fires: do not overlook the expired oxygen concentration. Anesth Analg 2013;117:1172-6.

43. Akhtar N, Ansar F, Baig MS, et al. Airway fires during surgery: Management and prevention. J Anaesthesiol Clin Pharmacol 2016;32:109-11.

44. Joo HS, Kapoor S, Rose DK, et al. The intubating laryngeal mask airway after induction of general anesthesia versus awake fiberoptic intubation in patients with difficult airways. Anesth Analg 2001;92:1342-6.

45. Stolz D, Chhajed PN, Leuppi J, et al. Nebulized lidocaine for flexible bronchoscopy: A randomized, double-blind, placebo-controlled trial. Chest 2005;128:1756-60.

46. Slinger P, Robinson R, Shennib H, et al. Alternative anesthetic technique for laser resection of a carinal obstruction. J Cardiothorac Vasc Anesth 1992;6:749-55.

47. Slinger PD, Campos JH. Anesthesia for Thoracic Surgery. In: Miller RD. editor. Miller's Anesthesia, 7th Edition. Philadelphia: Churchill Livingstone, 2009:1853.

48. Brown GW, Ellis FR. Comparison of propofol and increased doses of thiopentone for laryngeal mask insertion. Acta Anaesthesiol Scand 1995;39:1103-4. 
49. Ti LK, Chow MY, Lee TL. Comparison of sevoflurane with propofol for laryngeal mask airway insertion in adults. Anesth Analg 1999;88:908-12.

50. Brodsky JB. Bronchoscopic procedures for central airway obstruction. J Cardiothorac Vasc Anesth 2003;17:638-46.

51. Sutedja G, Koppenol W, Stam J. Nd-YAG laser under local anaesthesia in obstructive endobronchial tumours. Respiration 1991;58:238-40.

52. Conacher ID, Paes LL, McMahon CC, et al. Anesthetic management of laser surgery for central airway obstruction: A 12-year case series. J Cardiothorac Vasc Anesth 1998;12:153-6.

53. Madden BP, Datta S, Charokopos N. Experience with Ultraflex expandable metallic stents in the management of endobronchial pathology. Ann Thorac Surg 2002;73:938-44.

54. Filler RM, Forte V, Chait P. Tracheobronchial stenting for the treatment of airway obstruction. J Pediatr Surg 1998;33:304-11.

55. Baharloo F, Veyckemans F, Francis C, et al. Tracheobronchial foreign bodies: presentation and management in children and adults. Chest 1999;115:1357-62.

56. Chen CH, Lai CL, Tsai TT, et al. Foreign body aspiration into the lower airway in Chinese adults. Chest 1997;112:129-33.

57. Jillela S, Subrahmanyam R. Inhaled tooth in the bronchus: importance of early intervention. Br J Anaesth 2015;115:318-9.

58. Kanbur S, Evman S, Dogruyol T, et al. A Bronchopleurocutaneous Fistula Caused by Unexpected Foreign Body Aspiration: False Barley (Hordeum murinum). Ann Thorac Surg 2015;100:e125-7.

59. Kumar M, Goyal A, Gupta N, et al. Subcutaneous emphysema: Unique presentation of a foreign body in the airway. J Anaesthesiol Clin Pharmacol 2015;31:404-6.

60. Bain A, Barthos A, Hoffstein V, et al. Foreign-body aspiration in the adult: Presentation and management. Can Respir J 2013;20:e98-9.

61. Zhao Z, Gao Q, Song PL. A rare case of bilateral bronchial foreign body. Pak J Med Sci 2015;31:477-9.

62. Fidkowski CW, Zheng H, Firth PG. The anesthetic considerations of tracheobronchial foreign bodies in children: a literature review of 12,979 cases. Anesth Analg 2010;111:1016-25.

63. Brown KL, Shefler A, Cohen G, et al. Near-fatal grape aspiration with complicating acute lung injury successfully treated with extracorporeal membrane oxygenation. Pediatr Crit Care Med 2003;4:243-5.

64. Kamiyoshihara M, Ibe T, Kawatani N, et al. Successful treatment of a bronchopleural fistula after en masse lobectomy. J Thorac Dis 2016;8:E689-92.

65. Fiorelli A, Esposito G, Pedicelli I, et al. Large tracheobronchial fistula due to esophageal stent migration: Let it be! Asian Cardiovasc Thorac Ann 2015;23:1106-9.

66. Saraceni E, Vezzaro R, Boscolo A, et al. Images in Anesthesiology: Bronchopleural Fistula Caused by the Incorrect Placement of the Enteral Feeding Tube. Anesthesiology 2016;125:805.

67. Mulot A, Sepulveda S, Haberer JP, et al. Diagnosis of postpneumonectomy bronchopleural fistula using inhalation of oxygen or nitrous oxide. Anesth Analg 2002;95:1122-3.

68. Wong DC, Haindl W. The use of Technegasin the detection of a bronchopleural fistula. Clin Nucl Med 2000;25:548-9.

69. Poulin V, Vaillancourt R, Somma J, et al. High frequency ventilation combined with spontaneous breathing during bronchopleural fistula repair: a case report. Can J Anaesth 2009;56:52-6.
Cite this article as: Hatipoglu Z, Turktan M, Avci A. The anesthesia of trachea and bronchus surgery. J Thorac Dis 2016;8(11):3442-3451. doi: 10.21037/jtd.2016.11.35 